\title{
A MAQUINARIA JUDICIALIZANTE E O GOVERNO DE INFÂNCIAS DESIGUAIS
}

\author{
Giovanna Marafon ${ }^{1}$ \\ Universidade Federal Fluminense, Niterói-RJ, Brasil
}

\begin{abstract}
RESUMO. Este artigo realiza uma problematização da judicialização da vida e, mais especificamente, da judicialização da infância. Localiza na fabricação de infâncias desiguais no Brasil do século XX, uma circunstância histórica para pensar a proveniência e os efeitos da maquinaria judicializante. Propõe colocar em questão se o Código de Menores de 1927, como formulação jurídico-legal, seria suficiente para compreender o processo de judicialização da infância. Com o referencial de Michel Foucault, a discussão segue a proposta metodológica da genealogia, que permite ver, na heterogeneidade de acontecimentos, como se constituiu o enredamento de poderes e a aliança entre psiquiatria e judiciário na normalização das condutas. Dessa maneira, judicialização e normalização seriam processos complementares, mutuamente requisitados no governo da população. Para tanto, o conceito de governamentalidade mostra-se um instrumento estratégico para análise da judicialização como forma de governo da infância. Nesse sentido, a partir do tribunal de menores e dos comportamentos que nele estiveram em julgamento, pode-se compreender a cena judicializante, bem como algumas imagens que a difusão dessa forma-tribunal tem projetado.
\end{abstract}

Palavras-chave: Leis; infância; Foucault, M.

\section{THE JUDICIALIZING MACHINERY AND THE GOVERNMENT OF UNEQUAL CHILDHOODS}

\begin{abstract}
This article provides a problematization of the judicialization of life and particularly, of the judicialization of childhood. It finds in the manufacturing of unequal childhoods, in the twentieth century in Brazil, a historical event to think about the provenance and about the effects of the judicializing machinery. It proposes to put in question whether the Minors Code of 1927, as a legal-juridical formulation, would be enough to understand the judicialization of childhood process. Based on Michel Foucault's work, the discussion follows the methodological proposal of genealogy, that allows us to see in the heterogeneity of doings, how it was formed the entanglement of powers and the alliance between psychiatry and the legal power in the normalization of conducts. Thus, the judicialization and the normalization would be complementary processes, mutually requested in governing the population. Therefore, the concept of governamentality proves to be a strategic instrument for analysis the judicialization as a form of government childhood. In this respect, from the minors' court and behaviors that were there on trial, we can understand the judicializing scene, as well as some images that diffusion of court-form has designed.
\end{abstract}

Keywords: Laws; childhood; Foucault, M.

\section{LA MAQUINARIA JUDICIALIZANTE Y EL GOBIERNO DE INFANCIAS DESIGUALES}

RESUMEN. Este artículo realiza una problematización de la judicialización de la vida y, más específicamente, de la judicialización de la infancia. Localiza en la fabricación de infancias desiguales, en el siglo XX en Brasil, una circunstancia histórica para pensar de donde proviene, así como los efectos de la maquinaria judicializante. Propone poner en cuestión si el Código de Menores de 1927, como formulación jurídico-legal, sería suficiente para entender el proceso de judicialización de la infancia. Con el referencial teórico de Michel Foucault, la discusión sigue la propuesta metodológica de la genealogía, que permite ver, en la heterogeneidad de acontecimientos, como se constituyó el entramado de poderes y la alianza entre psiquiatría y poder judicial en la normalización de las conductas. De esta forma, judicialización y normalización serían procesos complementarios, mutuamente requeridos en el gobierno de la población. Por ello, el concepto de gubernamentalidad se muestra

1 Endereço para correspondência: Pontifícia Universidade Católica do Rio de Janeiro - Rua Marquês de São Vicente, 225, Prédio Cardeal Leme, $10^{\circ}$ andar, sala 1049, Caixa Postal 38097, Gávea, CEP 22.451-900, Rio de Janeiro-RJ, Brasil. E-mail: giovannamarafon@gmail.com. 
como un instrumento estratégico para el análisis de la judicialización como forma de gobierno de la infancia. En este sentido, a partir del tribunal de menores y de los comportamientos que en él estuvieron en juicio, se puede entender la escena judicializante, así como algunas imágenes que la difusión de esa forma-tribunal ha proyectado.

Palabras-clave: Leyes; infancia; Foucault, M.

Para iniciar este texto, a referência ao pensamento de Gilles Deleuze aponta uma direção. $\mathrm{Na}$ entrevista com concedida ao "Abecedário" Deleuze (1989) menospreza a infância que ele viveu (um "eu", em primeira pessoa). Diz ter sido uma criança qualquer; por isso the interessa muito mais a infância do mundo, a infância de qualquer criança. Uma criança, uma infância - com o artigo indefinido. É especialmente para uma forma-infância forjada historicamente que importa, ainda mais, estabelecer um olhar neste texto. Assim, emerge a inquietante pergunta: como se fez um menor no Brasil?

Sem a pretensão de esgotar a questão, uma vez que são várias as produções já existentes a respeito da história do período menorista e da legislação para os ditos menores no Brasil, o recurso à análise aqui se justifica porque se pretende, a partir do referencial desenvolvido por Foucault, esboçar uma genealogia da judicialização da infância no Brasil. Convém sublinhar que o termo judicialização não foi desenvolvido pelo autor em suas formulações, mas, é possível encontrar entre os livros, cursos e entrevistas de Foucault, uma variada gama de referências que permitem criar instrumentos estratégicos para tal análise.

\section{PARA PROBLEMATIZAR A JUDICIALIZAÇÃO}

Em "Nietzsche, a genealogia e a história" Foucault (1979) propõe a escrita da história genealógica, permitindo a emergência de uma história efetiva para a vida. Nela não se busca restituir as origens ou encontrar as raízes da pátria natal, nem uma continuidade, por isso o autor defende uma análise da descontinuidade e da heterogeneidade dos acontecimentos e, por fim, afirma uma história da invenção, em vez de crítica ao passado. A genealogia, tal como proposta por Foucault, visa à proveniência, às condições que permitiram a emergência de determinadas questões, saberes e formações de poder; não visa à origem, nem mesmo à verdade - sendo mais interessante pensar nos regimes de verdade que se tornaram aceitos e que validam certas práticas em detrimento de outras.

Problematizar a judicialização da infância torna-se uma maneira de estranhar práticas e discursos; é fazer problema onde não necessariamente haveria questões. Trata-se, então, da construção de um problema ou, mesmo, de recolocar o problema (Lemos \& Cardoso Jr., 2012), o que requer a desnaturalização daquilo que figura como dado. Nesse sentido, recorremos inicialmente à referência a um texto conhecido no campo das políticas públicas para a infância e juventude: o texto de Rizzini (2009) intitulado: "Crianças e menores: do pátrio poder ao pátrio dever. Um histórico da legislação para a infância no Brasil". Nesse texto encontra-se menção à expressão infância judicializada, no contexto histórico do primeiro Código de Menores no Brasil.

Essa expressão é, de saída, um caminho para pensar que a judicialização da infância poderia ser o marco temporal da emergência da legislação específica para os chamados menores no início do século $X X$, ou seja, a menoridade. Se o caminho fosse aquele, uma conclusão óbvia seria que a judicialização diz respeito ao enquadre jurídico e, consequentemente, judicial da infância; mas entendemos que não é somente isso, essa tendência tornou-se apenas o norte temporário do movimento, fazendo encontrar pontos de questionamento e de abertura a serem explorados neste artigo.

Entre relatos e análises sobre a história oficial da menoridade no Brasil, podemos encontrar análises como a que se segue, a qua aponta, conforme referido, a infância judicializada na virada do século XIX para o século XX:

A infância foi nitidamente "judicializada" neste período. Decorre daí a popularização da categoria jurídica "menor", comumente empregada nos debates da época. O termo "menor", para designar a criança abandonada, desvalida, delinquente, viciosa, entre outras, foi naturalmente incorporado na 
linguagem, para além do círculo jurídico (Rizzini, 2009, p. 113).

Na citação acima a judicialização é vinculada simplesmente à emergência do código de menores, ou seja, é uma referência ao fato de a infância ter sido alvo do desenvolvimento de uma lei que passou a disciplinar questões específicas. $\mathrm{Na}$ referência apresentada, a judicialização foi escrita para adjetivar uma prática: a da judicialização. Não obstante, interessa-nos tomar essa afirmação para em relação a ela estabelecer diferenciações $s$ divergências: judicialização da infância? Seria a judicialização de uma infância outra? Uma infância normal (das crianças) e uma infância dos menores?

Para esse período em tela, entendemos ser mais interessante falar em judicialização da menoridade ou, melhor, de constituição do menor e de montagem da judicialização. Com isso, o propósito é perceber como se foi montando o funcionamento da maquinaria judicializante e o que ela produzia, ou ainda, o que se produzia vinculado ao estabelecimento de seu modo de funcionar. Com essa perspectiva, delineamos como problema inicial a seguinte questão: ter-se-ia constituído uma legislação específica para a infância, ou melhor, para os chamados menores? Um direito de menores seria suficiente para conceituar a judicialização?

Assim, a maneira de problematizar a judicialização que aqui se propõe desloca-se daquela que simplesmente reconhece que parte da infância tenha passado a receber atenção/tutela jurídica. Evocando a heterogeneidade de acontecimentos, cumpre dizer ainda que era da parte da infância considerada anômala, ou seja, era dos menores que a legislação procurava dar conta/conter.

\section{JUDICIALIZAÇÃO E NORMALIZAÇÃO: ALIANÇAS}

Uma vez que era dos chamados menores que se tratava, a legislação para a menoridade pode ter sido apenas um dos aspectos presentes num processo mais amplo e heterogêneo de maquinar a judicialização com a tônica da normalização (Marafon, 2013). Foucault (2008a) afirma que a normalização disciplinar "consiste em primeiro colocar um modelo, um modelo ótimo que é construído em função de certo resultado, e a operação de normalização disciplinar consiste em procurar tornar as pessoas, os gestos, os atos, conformes a esse modelo" (p. 75). Com isso o autor afirma que quem é normal o é a partir da conformação à norma e por outro lado o anormal será aquele que não se conforma à norma; portanto, o que vem primeiro é a norma, ela tem caráter fundamental e primeiro. Dela se distinguem, a posteriori, normais e anormais.

Pensar a judicialização com a tônica da normalização disciplinar pode se configurar como um giro no que se habituou a dizer, fazer e até mesmo reiterar. Esse deslocamento, primeiramente, faz ver que o sistema legal se relaciona a um sistema de normas; e mais: a lei codifica uma norma, de modo que "a partir e abaixo, nas margens e talvez até mesmo na contramão de um sistema da lei se desenvolvem técnicas de normalização" (Foucault, 2008a, p. 74). O desenvolvimento de tal modo de olhar para o período da primeira legislação específica no âmbito da menoridade permite, ao se examinar o Código de Menores, ver como se acoplaram saberes parajudiciais ou extralegais que alimentaram o circuito de normalização das condutas, fabricando a categoria menor. É importante lembrar que menor não foi um termo cunhado em terreno estritamente jurídico, nem naturalmente incorporado na linguagem para além do círculo jurídico, pois já existia antes uma construção em meio às práticas policiais que contribuía para conformar, ou seja,, dar forma àquilo em que o menor se constituiu.

No que diz respeito à normalização das condutas, afirma Foucault (2001) que desde final do século XIX foi produzida uma espécie de reivindicação dos juízes em relação à medicalização de sua profissão, de sua função e de suas decisões. A institucionalização disciplinar do saber médico no campo jurídico traz a ideia de norma ancorada nas noções de normal e anormal e ao lado da medicina e da psiquiatria, e não do direito, da lei. Isto não fez sumir ou diminuir o recurso à lei, pelo contrário, a lei é cada vez mais colonizada pela norma nas diferentes legislações específicas para a infância, desde o começo do século XX até o presente.

Nesse sentido, a judicialização da infância indica uma íntima e necessária associação entre norma e lei. Por isso, embora Foucault (2001) tenha sugerido que a normalização pode se dar até mesmo na contramão do sistema da lei, o 
que se pode considerar sobre o processo de sistematização do direito de menores no Brasil é que a normalização se dá num encadeamento com o sistema da lei, e não em sentido contrário a ele. Além disso, como se poderá verificar na sequência do texto, havia já uma normalização policial anterior à promulgação do Código de Menores. Datada do século XIX, essa normalização faz pensar nas articulações entre práticas policiais e saberes psi.

Uma maneira de se perceber a normalização está na incorporação da norma pelo circuito jurídico, que serviu para justificar e requisitar um controle dos indivíduos ao nível da chamada periculosidade. Para isso, a instituição judiciária como um todo teve de buscar apoios exteriores a ela e, assim, convocar outros poderes laterais, uma rede de instituições de vigilância (a polícia) e correção (instituições psicológicas, psiquiátricas, criminológicas, médicas, pedagógicas). Mais do que isso, nessa aproximação de domínios não tão claramente separados, com algumas mimetizações de funções, vigilância e correção foram incorporadas pela polícia, e por seu turno, instituições psicológicas, psiquiátricas, criminológicas, médicas e pedagógicas incorporaram o modo de olhar e agir policial, o carcereiro, o vigia. O termo carcereiro é aqui colocado como função de quem exerce vigilância, correção e punição, função que se faz notar nos olhos/lentes dos profissionais também nas instituições de correção/normalização.

Mais ainda: no seio de modos de governo da vida não bastava punir. Uma novidade incorporada aos modos de proceder da justiça foi que o juiz pudesse simplesmente não mais punir, como afirmou Foucault (2001): "o duro ofício de punir vê-se assim alterado para o belo ofício de curar" (p.29) - ironia do filósofo francês em relação ao que poderia levar muitos a aderirem ao mais belo a que a cura parece associar-se, em detrimento da dureza e da frieza, geralmente identificadas à punição. Punir não, tratar - discurso cheio de intenções, como corrigir e reinserir. O que vai permitir a instalação de ilusões "re" (reeducação, ressocialização, reintegração), conforme assinala Batista (2008), é o bem-intencionado exame psiquiátrico. Nessa direção, Foucault (2003) apontou que se inventaram os exames no século XIX a partir de problemas jurídicos, judiciários, penais: exames como forma de análise dos indivíduos, em lugar do inquérito. Foram essas novas formas de análise nascidas no século XIX, momento de formação da sociedade capitalista, que deram origem à sociologia, à psicologia, à psicopatologia, à criminologia e à psicanálise, todas elas ciências de exame.

No âmbito judiciário, os discursos presentes nos laudos psiquiátricos concorrem para determinar a liberdade ou a detenção de um homem, têm um poder de vida e de morte e, ainda, fazem rir! Rir do caráter ubuesco, ridículo e grotesco de tais discursos. Destaque-se que o adjetivo ubuesco é usado por Foucault (2001) e refere-se à peça francesa, do começo do século XX, "Ubu rei" (de S. Jerry). O termo ubuesco diz do grotesco, autoritário, injurioso e, ao mesmo tempo, ridículo.

Voltemos aos discursos presentes nos laudos psiquiátricos: estes discursos, plenos dos mais variados moralismos e preconceitos, proferem sentenças que, vistas de perto e com atenção, mostram quanto estão alheios às regras de enunciação do discurso científico e também do direito. Com isso, Foucault (2003) diz que o tribunal, e também as instituições qualificadas para enunciar a verdade, como a ciência, veiculam enunciados com efeitos de verdade e poder: "uma espécie de supralegalidade de certos enunciados na produção da verdade judiciária" (p. 14).

Esses discursos são sustentados por duas instituições: a judiciária e a médica. Situado a meio caminho de ambas, o exame psiquiátrico vai olhar não somente para o delito, mas para toda uma série de outras coisas que não são o delito. Vai colocar em seu campo de avaliação também os comportamentos, as maneiras de ser do indivíduo. Vai procurar, nessas maneiras, a causa, a origem, a motivação, o ponto de partida do delito. São introduzidos aí dobramentos, duplos sucessivos entre delito e algo mais. Foucault (2002a) afirmou que a intervenção da psiquiatria "desde os anos 1820 , na justiça penal é o sinal de que começa muito cedo o reino de sua indiscrição generalizada" (p. 326). Reino de indiscrição generalizada ou, ainda, generalização indiscreta da psiquiatria, com suas pretensões de função permanente e universal é o que será visto daí por diante. Por isso o filósofo francês afirmou que "a partir do século XIX, todos nos tornamos psiquiatrizáveis" ( $p$. 326), possuidores de uma loucura possível, com a psiquiatrização de todos e de qualquer um, em qualquer lugar: nas relações familiares, pedagógicas, profissionais e outras. 
$\mathrm{Na}$ psiquiatrização do judiciário, o alvo de apreensão do que está situado além do crime são as condutas. Não é a lei que elas infringem. Essas condutas, em exame, infringem qualificações morais, regras éticas, a exemplo dos termos referidos nesse gênero de discurso, destacados por Foucault (2001), tais como: imaturidade psicológica, personalidade pouco estruturada, profundo desequilíbrio. Não se referem a condutas delituosas, referem-se simplesmente a condutas; portanto as condutas consideradas irregulares é que serão punidas, mesmo aquelas que não sejam criminosas, fazendo um duplo psicológico e moral do crime, uma ponte entre as categorias jurídicas e as noções médicas (vale acrescentar psiquiátricas, psicopatológicas e psicológicas). Como efeito, também a punição não será do crime em si. A ação punitiva do poder judiciário vai recair sobre técnicas de transformação dos indivíduos. Este é um aspecto importante nessa maquinaria, que permite ver a produtividade das tecnologias de poder: o poder de normalização se explicita nesse encontro médico-judiciário, apoiando-se ao mesmo tempo na instituição judiciária e no saber médico. A "cena teatral do fórum" (Foucault, 2001, p. 32) vai ser a cena da normalização das condutas.

\section{COMO SE FABRICARAM "MENORES": O GOVERNO DE INFÂNCIAS DESIGUAIS}

No Brasil a década de 1920 foi profícua em criar mecanismos e aparelhos específicos para operar a gestão calculista da população. Foram criadas novas regras, normas e governos sobre a infância, definindo-a de formas desiguais. Para os menores, tidos como problema social (o que correspondia a problema policial), em 1923 foi criado o "Regulamento de Proteção aos Menores Abandonados e Delinquentes" - documento que criava o Juízo de Menores e, subordinado a este órgão, o Abrigo de Menores, que receberia, em caráter provisório, menores abandonados e delinquentes - a face negativa da infância. Previa, ainda, uma escola para oferecer educação física, moral, profissional e literária às meninas desprotegidas/abandonadas.

O primeiro Código de Menores (Código de Mello Mattos, Decreto $n^{\circ} 17.943$, de 12 de outubro de 1927) regulamentava as formas de proteção (tutela) e correção destinadas apenas aos menores 18 anos de idade, de ambos os sexos, abandonados ou delinquentes; ou seja, todos os demais (não abandonados ou não delinquentes) não mereciam a ação desse instrumento jurídico, saturado de influência policial e normativa, com consequências sociais, policiais, educacionais e correcionais. O que está presente no Código de Menores é um pensamento negativo - o do abandono e da delinquência, ambas apontando para a desordem, para aquilo que foge da suposta ordem. Essa desordem é o que resta. É o resto das crianças, é o menor. O código legal é a técnica que anima esse princípio negativo. Como afirmou Foucault (2008a), a lei imagina o negativo - as coisas que poderiam ser feitas e não devem ser feitas, ou seja, aquilo que é proibido.

Desse modo, é possível compreender que não somente o Código foi uma produção histórica, mas também o menor 0 foi. Interessante pensar o relevo que atravessa a paisagem e desloca $o$ olhar se estivermos dispostos, como afirmou Ramos do Ó (2009) a "problematizar a forma como crianças e jovens foram eles mesmos constituídos historicamente também como um problema" (p. 23); e para que se consolidasse tal perspectiva de problema, houve enorme contribuição das práticas policiais, da medicina, da psicologia e da assistência social na construção normativa do referido Código de Menores e, sobretudo, na construção do trinômio que associava periculosidademenoridade-pobreza. A implantação do Código de Menores trazia ainda ressonâncias de outras práticas que foram a ela se coadunando, especialmente o funcionamento das instâncias policiais e da própria justiça criminal e a incorporação que o Código fez de mecanismos parajurídicos, entre eles, principalmente o educativo e correcional.

Cumpre ainda destacar que, embora aqui se reporte a uma legislação específica para a menoridade datada de 1927, a preocupação médico-social com soluções higienistas voltadas aos menores já se percebe na passagem do Império à Primeira República brasileira. Do mesmo modo, intervenções policiais desse mesmo período que antecede a legislação específica já tratavam de nomear, classificar e intervir no que se configurava, no bojo dessas práticas, como o menor. Com isso é possível observar, nos âmbitos médico-social e policial, uma duplicidade forjando o menor.

No âmbito policial, uma paisagem a irromper na história dos menores e cortar sua narrativa 
linear é o trabalho de pesquisa desenvolvido por Vianna (1999). Na investigação realizada, a autora recolheu um conjunto variado e bastante heterogêneo de 1.800 registros localizados no Arquivo Nacional, relativos ao recolhimento e à classificação dos chamados menores por agentes policiais. O que Vianna percebeu era que a polícia, enquanto instância da administração estatal - a Polícia do Distrito Federal - tinha importância decisiva na definição de sentidos e formas de intervenção sobre o que já se designava como menor. Assim, em vez de tratar a polícia como agente secundário, naquela pesquisa realizada na década de 1990 Vianna (1999) preferiu privilegiar a ação da polícia no período de 1910-1920, o que não desmerecia a importância de outras formas de intervenção (como assistência caritativa e filantrópica ou, ainda, a ação médico-higienista). $O$ que sobressai na pesquisa realizada é a relação entre polícia e menores, o que fez a autora indicar:

... ao contrário do que se poderia pensar, não é o código o responsável pela generalização do termo ou dos significados nele implicados. Em vez disso, é possível tomar o código como a formalização de uma lógica eminentemente policial, em voga pelo menos uma década antes de sua promulgação (Vianna, 1999, p. 40).

Esse apontamento encontra correlações com o que apresentou Foucault (2008b): "No século XVIII, fim do século XVIII, início do século XIX, aparece na teoria política e na teoria do direito germânico essa noção de Estado de direito" (p. 232). Algo intrigante na genealogia das formas de governo, empreendida por Foucault, é a observação de que o Estado de direito se definiu naquele momento em oposição a duas questões: a primeira, como diz ele, em oposição ao despotismo - identificado com a vontade do soberano, o caráter e a forma obrigatória das injunções do poder público; e a segunda, o Estado de direito opor-se também ao Estado de polícia - o qual estabelece um continuum administrativo que "da lei geral à medida particular, faz do poder público e das injunções que este impõe um só e mesmo tipo de princípio e lhe concede um só e mesmo tipo de valor coercitivo" (Foucault, 2008b, p. 232). Está aí o nível da regulamentação da vida.
No contexto do Estado de Polícia, o poder de polícia refere-se ao poder/dever do Estado de organizar a vida, daí a ideia trazida por Foucault (2006) de um continuum administrativo. O elemento central das formas de governo é o governo da família, que se realiza em balizar a continuidade ascendente e descendente. A dimensão de uma continuidade ascendente das formas de governo começaria pelo governo de si próprio, estendendo-se depois ao governo da família, de seus bens e, finalmente, ao governo do Estado (a pedagogia do Príncipe). $\mathrm{Na}$ continuidade descendente, o governo iria do Estado bem-governado aos pais de família que soubessem bem governar suas famílias, suas riquezas, seus bens e sua propriedade até os indivíduos que se comportassem como deviam. A polícia seria justamente essa linha descendente, "que faz repercutir até na conduta dos indivíduos ou na gestão das famílias o bom governo do Estado" (Foucault, 2006, p. 288).

Há momentos em que o Estado de polícia pode inclusive coincidir com o despotismo, mas via de regra eles diferem no fato de, no despotismo, tudo o que pode ser injunção do poder público origina-se tão somente da vontade do soberano, enquanto no Estado de polícia, qualquer que seja a origem do caráter coercitivo das injunções do poder público, há entre elas um continuum da lei e suas prescrições gerais e permanentes à regulamentação por meio de decisões conjunturais, transitórias, locais, individuais.

A paisagem muda. $O$ que se percebe a partir desse desenvolvimento dado por Foucault (2006) é que o Estado de polícia é condição (ainda que com argumento de oposição) para o desenvolvimento do Estado de Direito. Mais que isso, como indicou Vianna (1999), pensando na situação específica do Código de Menores, no interior do Estado de Direito estará a lógica policial - portanto, nas entranhas do Estado de direito, com seus institutos jurídicos, impera a lógica policial (Marafon, 2013).

Anteriormente ao Código de Menores houve ideias, discursos e práticas que tiveram imensa influência na fabricação dos menores como produtos policiais e dos destinos a eles oferecidos, tendo influência, inclusive, sobre o que veio a ser o Código. A gestão policial colocava o menor como finalidade e instrumento de uma governamentalidade. Foucault utilizou-se da noção de governamentalidade sem configurar o conceito em um enquadramento fechado; pelo 
contrário, é possível perceber, no desenvolvimento que deu ao termo, alguns deslocamentos do próprio percurso analítico do autor. No curso no Collége de France, em 1978 ("Segurança, território, população"), a governamentalidade foi definida por Foucault (2008a) como um conjunto de instituições, procedimentos, cálculos, táticas e estratégias que permitem o governo da população; já no curso de 1979 ("Nascimento da Biopolítica"), o conceito governamentalidade foi definido pelo pensador francês como chave para a análise das relações de poder em geral e sobressai a noção de governamentalidade como conjunto, "maneira de condução da conduta dos homens" (Foucault, 2008b, p. 258).

Anteriormente, no curso "Os Anormais", Foucault (2001) referiu que a "arte de governar" (p. 60) que a Idade Clássica elaborou se dá precisamente nos seguintes termos: "o 'governo' das crianças, o 'governo' dos loucos, o 'governo' dos pobres e, logo depois, o 'governo' dos operários" (p.60). Cumpre destacar o entendimento de um governo diferencial das crianças, destacando a parte anormal - os chamados menores. Foucault viu em tal sentido de governo a implantação de todo um aparelho governamental, um aparelho de Estado, com prolongamentos e apoios em diversas instituições, com efeitos de normalização; e esse poder de normalização "só pode funcionar graças à formação de um saber, que é para ele tanto um efeito quanto uma condição de exercício" (Foucault, 2001, p. 65).

Com efeito, em relação ao governo da infância, no Brasil o começo do século XX caracterizou a imagem do problema da menoridade como problema social, o que significa dizer que estava cristalizada uma massa diversificada de crianças pobres passíveis de serem enquadradas em classificações que indicassem uma situação anormal em referência a um modelo primeiro, normal, de infância e família. O dispositivo disciplinar atuava dentro da instituição de polícia e, com uma força centrípeta, em direção aos menores. Se por um lado havia as instituições filantrópicas destinadas à caridade e instituições que combinavam assistência pública e privada, que visavam a combater as causas da mortalidade ou do abandono, por outro lado estavam os destinos policiais para aqueles recolhidos e apreendidos nas ruas, cuja ênfase, dando sentido ao termo menor, estava no aspecto correcional (normalizador, portanto) na prevenção (com preocupações de intervenção sobre o futuro) e no abandono - leia-se, não pela necessidade de amparo do jovem, mas pela ameaça de desordem que portariam os menores; sendo assim, importava afastá-los do convívio das ruas, importava conduzir as condutas daqueles jovens e regular suas vidas, gerindo-lhes a liberdade que, em última instância, não poderia ser vivida sem regulação.

Com isso, tanto o problema da proteção quanto o da punição, segundo Vianna (1999), remetiam à identificação de sujeitos duplamente privados de autonomia: "por serem menores em geral, e por serem menores com características consideradas irregulares" (p. 33). Sendo assim, embora o termo menor "tenha suas raízes na produção jurídica, consolidou-se e generalizouse em boa medida por meio da ação policial" (Vianna, 1999, p. 43). Essa ação policial não se dava apenas numa lógica punitiva ou investigativa, mas, sobretudo, estava voltada à identificação daqueles indivíduos tidos como potencialmente perigosos. Tratava-se, visivelmente, de um assunto policial, do domínio da polícia, que incluía preocupação pedagógica com a correção/transformação dos menores a ser realizada nas instituições para onde eram remetidos e internados.

Havia uma aura de cientificidade de saberes que alimentava as práticas do cotidiano policial, e entre esses saberes estava a psicologia criminal (que visava a distinguir o homem criminoso do homem normal) e o "curso de história natural dos malfeitores [que] frisava a identificação das classes perigosas da sociedade" (Vianna, 1999, p. 49). Para tanto, esse curso utilizava um arsenal de preconceitos, tidos como informações objetivas a respeito das características das pessoas - supostos criminosos - que incluía gírias e jargões falados, tatuagens no corpo e, sobretudo, aspectos raciais. Vale lembrar que o Brasil vinha de um período de mais de trezentos anos de escravidão e que, não bastasse isso, os ex-escravos eram alvo desse tipo de olhar vigilante.

No cenário liberal e republicano, o Estado, sob a forma de polícia, assumia a gestão da população pobre dos centros urbanos. Gerindo liberdades, legalidades e ilegalidades, assumia a obrigação de garantir a vida (sob gestão governamental) e o modo como essas vidas se organizavam. Ser identificado como menor produzia uma captura da condição de gerir o seu 
destino e, a partir daí, a submissão de seus argumentos à decisão policial. Os policiais julgavam mais as pessoas do que os atos praticados. Faziam um juízo moral dos suspeitos. Além disso, a ação dos juízes era diminuída em relação à da polícia, pois, em consonância com a lei complementar de 1899, os delegados de polícia eram responsáveis por conduzir os processos de contravenção, o que poderia se dar pela simples não inserção no mercado de trabalho, cabendo ao judiciário apenas proferir a sentença final.

Em meio à governamentalidade que tinha de gerir as subjetividades na passagem de um regime escravocrata à República dos cidadãos considerados livres, havia imenso esforço em produzir a figura do trabalhador livre. A figura do trabalhador estava em compasso com os interesses econômicos vinculados ao capitalismo liberal da época.

Assim, a promulgação do Código de Menores em 1927 já veio impregnada da lógica policial que o precedeu, judicializando de modo ampliado as práticas que já aconteciam no cotidiano policial das delegacias e das instituições de internamento dos menores. A implementação do Código pode ser vista como o momento em que "juridicamente, a menoridade deixa de figurar como uma condição a ser levada em conta nos diversos tipos de códigos legais para se tornar um objeto específico de normatização" (Vianna, 1999, p. 169). Na realidade, isso quer dizer que o Código de Menores adotou uma classificações dos menores igual à que fazia a prática policial. Com o Código, então, passaram a se dar intervenções de cunho policial e judiciário, indicando muito mais articulações entre um mecanismo e outro do que se suporia inicialmente. Essa constatação levou Vianna (1999) a tirar, entre outras conclusões, a de que a eficácia do Código estaria não tanto no seu grau de formalização propriamente jurídica, mas em sua operacionalidade, ou em última instância, podemos dizer que estaria na maneira como opera, funciona, e no que produz.

$\mathrm{Na}$ conjuntura do Código de Menores amparado pela lógica do Estado de direito convém relembrar a assertiva de Foucault (2008b) segundo a qual a constituição do Estado de Direito, agindo em referência à lei e no âmbito da lei, seria uma resposta para fazer frente ao Estado de polícia e ao despotismo. Neste sentido, o Estado de direito é apresentado historicamente como a alternativa positiva que também diferenciou ações coercitivas do poder público, no espaço definido pela forma da lei, daquelas medidas chamadas administrativas, que representavam decisões particulares do poder público. Assim, “... primeiramente, o Estado de direito é definido como um estado em que os atos do poder público não poderão adquirir valor se não forem enquadrados em leis que os limitem antecipadamente". (Foucault, 2008b, p. 233). O segundo aspecto do Estado de direito, também referido por Foucault, “... são distinguidas, em seu princípio, em seus efeitos e em sua validade, as disposições legais, de um lado, expressão da soberania, e as medidas administrativas, de outro" (Foucault, 2008b, p. 233).

Percorridos os aportes acerca da polícia e do direito, na remontagem das proximidades e conexões entre eles, extraímos um sentido preciso para a judicialização e o governo da infância. Uma possibilidade específica para pensar a judicialização se dá por meio da análise da infração jurídico-legal acoplada à disciplina, e aqui fica evidente a definição jurídico-legal no campo da menoridade ativando e sendo ativada pelo funcionamento disciplinar, que incluía o olhar da vigilância policial. Desse modo a lei faz ativar os circuitos para a normalização continuar a acontecer. Nesse aspecto, a judicialização se apresenta como um processo que está acoplado à normalização dos gestos, das pessoas, dos atos. Neste sentido emerge uma indicação: judicialização e normalização requerem-se mutuamente (Marafon, 2013). A lei é a formalização do negativo imaginado (proibido) que precisará ser trabalhado pela complementaridade disciplinar. Uma convoca a outra: lei e disciplina.

\section{GOVERNO DA POPULAÇÃO ATRAVÉS DA FAMÍLIA}

A articulação entre mecanismos de educação, saúde e segurança pôde ser usada e contribuiu para fazer funcionar a gestão da população como conjunto de indivíduos, o que precisou acionar regulamentações sobre a família, o casamento, a mulher e, principalmente, sobre a infância. Foi por meio da defesa dos interesses das crianças que a tutela permitiu uma intervenção, naquele momento, basicamente estatal, corretiva e supostamente salvadora, como apontou Donzelot (2001), sobre 
o desenvolvimento da passagem de um governo das famílias para um governo através da família. O pelo bem-estar dos cidadãos e pelos interesses das crianças que se justificaram as ações morais, especialmente para agirem tendo em conta a intervenção nas famílias pobres - as que portavam o fantasma da anormalidade consideradas inadequadas, desestruturadas, degradadas moralmente. Vale apontar que até hoje essa moralização se mantém em alguma medida e não raramente os discursos e as práticas de diversos especialistas se ocupam em apontar as ditas famílias desestruturadas como responsáveis por algo que tenha se passado na vida de seus membros.

Com o Código de Menores, as estratégias de poder se edificaram em torno dos juizados de menores, dos espaços de correção com orientação correcional repressiva, baseados em reformatórios, casas de correção, patronatos agrícolas e escolas de aprendizagem de ofícios urbanos (tal como já acontecia na década anterior, sob ação policial) e na escolarização obrigatória. No decorrer do tempo, a internação em instituições especializadas foi uma tônica dominante no Brasil, tanto que hoje, ao se problematizar a questão, fica difícil perceber alguém, por mais excluído que pareça, fora de uma rede institucional. Assim, o olhar que se materializa na produção de um saber num fichário, seja de hospício, abrigo, delegacia de polícia ou serviço de assistência à infância, dará conta de registrar alguma parte da vida, "... sujeita à classificação na ordem de um desvio qualquer, mesmo que nenhuma providência seja tomada para melhorar sua vida, o que é o mais provável" (Lobo, 2008, p. 262). Tal situação é comum acontecer também em nosso presente, com ações sobre as famílias, as quais têm suas vidas enredadas na maquinaria judicializante.

Aqui se faz necessária uma diferenciação das técnicas de normalização através das famílias, que produziram caminhos diferentes para as famílias burguesas e para as famílias pobres. Para descrever como se produziu o anormal, Foucault (2001) estudou e especificou antecedentes desse anormal: de um lado a "engrenagem psiquiátrico-familiar" (p. 351) e, de outro, a "engrenagem psiquiátrico-judiciária" ( $p$. 351). A engrenagem psiquiátrico-familiar vai agir na família burguesa, a qual sofre quase exclusivamente a chamada cruzada antimasturbatória - com nítida influência cristã e confessional, agora transformada em problema médico. No decorrer do século XVIII a sexualidade das crianças e dos jovens dessas famílias foi colocada sob vigilância. 0 confessionário foi deslocado para o consultório médico. A caça à masturbação possibilitou a organização da família burguesa na forma celular, conjugal e nuclear e demandou a ação dos médicos sobre o diagnóstico dos perigos que rondavam a constituição daquele modelo familiar.

Para a família popular, ou, como diz Foucault (2001), para a família do proletariado urbano que se constituía no começo do século XIX, voltaram-se outros temas. Para a família pobre, o perigo era outro e a engrenagem era psiquiátrico-judiciária: primeiro, em torno do casamento monogâmico, a ser disciplinado por meio de livros, de campanhas, de políticas habitacionais, etc.; depois, no que tange à distribuição espacial da família, da divisão dos espaços da casa: "nada de corpo a corpo, nada de contatos, nada de misturas" (Foucault, 2001, p. 344).

Embora fossem modelos referentes à sexualidade, havia dois modelos distintos, dois modos de sexualização da família,ou dois modos de familiarização da sexualidade. Enquanto no modelo da família burguesa se demandava intervenção e racionalidade médica, no modelo da família proletária a convocação era a de uma arbitragem, da decisão de tipo judiciário - ou seja, do tribunal. Na família pobre

\begin{abstract}
... é o juiz, ou o policial, ou todos esses substitutos que hoje, desde o início do século $X X$, são todas as instâncias de controle social: é a assistente social, é todo esse pessoal que deve intervir na família para conjurar esse perigo de incesto que vem dos pais ou dos mais velhos (Foucault, 2001, p. 346).
\end{abstract}

\section{OS TRIBUNAIS DA NORMALIZAÇÃO}

Um aspecto importante que se desdobra da judicialização necessariamente implicando a normalização é o tribunal - lugar de cenas judicializantes. O destaque aos tribunais para menores foi dado por Foucault (2001) na lógica da normalização por intermédio dos exames, que fornecem informações psicológicas, sociais e médicas sobre as pessoas. "É um tribunal da perversidade e do perigo, não é um tribunal do crime aquele a que o menor comparece" 
(Foucault, 2001, p. 50). Não é só no tribunal para os chamados menores, mas cumpre referir que essa forma de tribunal da perversidade e do perigo se instala também nos espaços de administração penitenciária, o que inclui, ao longo da história brasileira, a correção e internação dos menores - mais um grande internamento, uma marca da sociedade capitalista. Em tais espaços ditos correcionais, os serviços médico-psicológicos são continuamente requisitados, e no interior deles pode estar a forma-tribunal. Além disso, é nessas instituições, nesses espaços - que parecem humanitários, terapêuticos, preventivos e cientificamente respaldados - que se instalam “... os centros para jovens em perigo, os reformatórios, dirigidos por pessoas com jeito de assistentes sociais, educadores, médicos, mas que, finalmente, são policiais" (Foucault, 2001, p. 288). As profissões são diferentes, porém não tão diversas na tônica que assumem: a da função comum que os encadeia juntos. Essa função é a de carcereiro e os que a exercem tornam-se vigilantes dos desvios e das anormalidades de "existências marginais que não são nem verdadeiramente criminais nem verdadeiramente patológicas" (Foucault, 2002b, p. 288).

Nesses espaços que também abrangem o tribunal, seja nos locais pretensamente assépticos do cumprimento das medidas socioeducativas (com toda a sorte de torturas, maus-tratos e humilhações que lá acontecem até hoje), seja nos chamados abrigos (que recebem crianças e adolescentes majoritariamente pobres), o que se quer saber é do cumprimento da sanção ou da medida, da evolução do indivíduo (essa grande falácia no terreno da fabricação da delinquência), do tão falado nível de periculosidade, cuja aferição segue sendo tão almejada; e não são só essas instituições, mas também outros espaços e tempos menos facilmente identificados à judicialização - como as escolas e as práticas de mediação de conflitos, os conselhos tutelares, as famílias, as relações afetivas e as amizades - estão também cheios de tribunais e de profissionais policiais (Marafon, 2013). Esses espaços e condutas são subjetivados pela maquinaria judicializante que se instala levando sua forma-fôrma: o tribunal. Assim, essa imagem do tribunal em diversos espaços, não apenas na instituição judiciária propriamente dita, é característica da judicialização da vida, operando no plano da arbitragem das condutas.

\section{VIDAS SEM COMPARAMENTO}

Embora os discursos e as práticas judicializantes e de governo da infância fossem dominantes no período em tela, havia também outros modos de pensar e propor práticas para a infância. Essas outras possibilidades foram excluídas de legitimidade na governamentalidade da época. Ficaram à margem, nas bordas, produzindo vozes dissonantes. Em conferência realizada em Paris no dia 4 de janeiro de 1921, Faure (1921/2009), numa conferência intitulada "A criança", apresentou o que pensava "Sou um adversário ferrenho do que é chamado classificação; do sistema que consiste em fazer com que as crianças entrem em competição, para reconhecer uma como primeira da classe, outra como segunda, uma outra ainda como última. (Faure, 1921/2009, p. 29). Afirmou ainda:

A coerção tem inconvenientes graves
porque ela só funciona com seu cortejo
de punições e recompensas. Ela tem o
inconveniente de regulamentar todos os
atos da criança, de catalogá-los como
permitidos ou proibidos, de categorizá-
los como atos recompensados e atos
punidos (Faure, 1921/2009, p. 36 ).

Faure - anarquista, pedagogo, poeta, compositor e jornalista acusado, julgado e considerado inocente - fora acusado da autoria de um atentado a bomba contra a câmara dos deputados no processo conhecido como Processo dos trinta, juntamente com vários outros anarquistas. Foi um julgamento histórico em que o anarquismo estava na condição de réu. Mais uma vez, o tribunal. O modo intempestivo de Faure lança inquietantes questões atuais, inclusive para o presente vivido. Enquanto o sistema de classificações torna-se cada vez mais sofisticado e naturalizado nas mentes de pais, professores, alunos, jovens, diretores de empresas e dos chamados recursos humanos, a discordância libertária alimenta a resistência ao intolerável cotidiano classificatório, meritocrático e de efeitos nefastos para todos. Para os defensores da livre-concorrência do mercado e das pessoas, as ideias libertárias são uma afronta a seus princípios - princípios esses 
que regem a lógica do capital e regem também as motivações empreendedoristas da expertise psi, que circula socialmente, dando lições aos pais e educadores no sentido de bem recompensar e bem punir as consideradas animalidades infantis.

Como afirmou Guattari (Guattari \& Rolnik, 1986) “... é desde a infância que se instaura a máquina de produção de subjetividade capitalística, desde a entrada da criança no mundo das línguas dominantes" (p. 40). Já se entrevê aí a produção de subjetividades, com a formação de campos de problemas sociais e policiais agregando a vigilância dos comportamentos mais sutis e corriqueiros, alcançando até o mais fino dos comportamentos individuais. Por outro lado, na poesia "Memórias inventadas", diz Manoel de Barros (2008):

\begin{abstract}
Cresci brincando no chão, entre formigas. De uma infância livre e sem comparamentos. Eu tinha mais comunhão com as coisas do que comparação. Porque se a gente fala a partir de ser criança, a gente faz comunhão: de um orvalho e sua aranha, de uma tarde e suas garças, de um pássaro e sua árvore. Então eu trago das minhas raízes crianceiras a visão comungante e oblíqua das coisas (p. 187 - itálicos do autor).
\end{abstract}

Para exercitar a experiência de visões oblíquas, a película "Os incompreendidos" (Truffaut, 1959) mostra as institucionalizações da infância no século XX. O personagem Antoine, frequentemente apontado pela crítica como um recurso autobiográfico de Truffaut, se tomado numa perspectiva ético-estética da diferença, em vez de afirmar biografias psicologizadas, poderia convidar a pensar - como afirmou Deleuze (1989) -, não na infância do eu, mas sim na infância do mundo. As lentes aguçadas mostram a escola francesa dos anos 1950, a hierarquia, o professor sempre atento a qualquer desvio para reprimir e punir as crianças. Apresenta-se a insuportável e tediosa experiência infantil e disciplinar naquele regime: da escola passa-se pela família até chegar ao reformatório.

Também no Brasil, às políticas praticadas nos estabelecimentos de internação ou reformatórios como o que prendeu Antoine, importava o ajustamento social, a regulação moral dos considerados desassistidos. A educação mostrava sua face menos benevolente, de treino moral. Mostrava-se a maquinaria judicializante em um continuum médico-judiciário que se estabelece com as medidas corretivas, medidas de readaptação e de reinserção. Tal maquinaria desdobra-se ainda numa espécie de continuum da proteção. É oportuno trazer à tona a qualidade de ações que o argumento da proteção encadeia. Trata-se de um continuum protetivo do corpo social: da instância médica de cura (polo terapêutico) à instituição penal propriamente dita (a prisão ou, ainda, o cadafalso - polo judiciário). Como uma real cadeia disciplinar ininterrupta de instituições médico-judiciárias, esse continuum responde ao perigo e assenta-se no medo e na moralização, tal como acontecia também com as intervenções policiais que contribuíram para engendrar 0 menor no começo do século XX no Brasil.

\section{CONSIDERAÇÕES FINAIS}

O duplo circuito psiquiátrico-familiar e psiquiátrico-judiciário configurou caminhos distintos, e mesmo, desiguais, a serem engendrados e percorridos por diferentes grupos no sistema de defesa e proteção social no Brasil, posteriormente também chamado de sistema de garantia de direitos (a partir do Estatuto da Criança e do Adolescente, 1990). Como uma cadeia produtiva, esse duplo circuito foi e segue gestando seus produtos-problemas. A constituição da figura do policial, com seu correlato desempenho, migrou para o território judiciário e, incorporada, fez da figura do juiz uma imagem valorizada e enaltecida. Muitos querem ser um pouco juízes e um pouco policiais das prisões (prisões-estabelecimentos, prisões-escolas, prisões-famílias, prisõesmentais, prisões-infância, prisões subjetivas, etc.).

Com as análises aqui desenvolvidas, apoiadas no referencial representado por Foucault, é possível afirmar que a normalização necessita da forma-tribunal para ser formada. Em vez de a judicialização ser uma mera consequência, a análise dessas formações históricas no campo do direito e da assistência à infância no Brasil, desde o final do século XIX, mostra o substrato judiciário como condição e efeito da normalização.

A maquinaria judicializante, com seus projetores, faz passarem incidências nas quais os chamados trabalhadores do social ou, melhor, trabalhadores das instâncias de controle social, 
revestem-se do manto legalista-punitivocorrecional que recobre o juiz. O juiz se espalha e espelha, então são vários juízes; juízes paralelos; imagens espelhadas e duplicadas, espelho do espelho. O juiz exerce a nobre função de curar e tratar, já os trabalhadores do controle social querem vigiar, coibir, punir, classificar, identificar perigos, encaminhar para estabelecimentos. A maquinaria judiciária também emite partículas que interferem na realidade. Os microtribunais passam pelas fendas judiciárias e se sobrepõem aos demais estabelecimentos e funcionamentos sociais. Imagens da judicialização da vida.

\section{REFERÊNCIAS}

Barros, M. (2008). Memórias inventadas: a terceira infância. São Paulo: Planeta do Brasil.

Batista, V. M. (2008). Adeus às ilusões "re". In C. Coimbra, L. S. M. Ayres, \& M. L. Nascimento. (Orgs.). Pivetes: Encontros entre a Psicologia e o Judiciário (pp. 195-199). Curitiba: Juruá.

Deleuze, G. (1989). O abecedário de Gilles Deleuze. (Descrição de entrevista realizada por Claire Parnet, com direção de Pierre-Andre Boutang). Recuperado em junho de 2013, de http://stoa.usp.br/prodsubjeduc/files/262/1015/Abecedario+ G.+Deleuze.pdf.

Donzelot, J. (2001). A polícia das famílias. (M. T. da Costa Albuquerque, trad.) 3 ed. Rio de Janeiro: Graal.

Faure, S. (2009). A criança. Verve, 16, 13-47. Recuperado em junho de 2013, de: http://uww.nusol.org/verve/pdf/verve16.pdf. (Original publicado em 1921).

Foucault, M. (1979). Nietzsche, a genealogia e a história. In M. Foucault. Microfísica do poder (pp. 12-23). (R. Machado, Trad.). Rio de Janeiro: Graal.

Foucault, M. (2001). Os Anormais. (Curso no Collège de France, 1974-1975). (E. Brandão, Trad.). São Paulo: Martins Fontes.

Foucault, M. (2002a). O asilo ilimitado. In M. B. Motta. (Org.). Problematização do sujeito: psicologia, psiquiatria e psicanálise (pp. 324-328). (Col. Ditos e Escritos, Vol. 1). Rio de Janeiro: Forense Universitária.

Foucault, M. (2002b). O grande internamento. In Motta, M. B. (Org.). Problematização do sujeito: psicologia, psiquiatria e psicanálise (pp. 285-296). (Col. Ditos e Escritos, Vol. 1). Rio de Janeiro: Forense Universitária.
Foucault, M. (2003). A verdade e as formas jurídicas. Rio de Janeiro: NAU.

Foucault, M. (2006). A "Governamentalidade" (1978). In Motta, M. B. (Org.). Estratégia, poder-saber. (pp. 281-305). (Col. Ditos e Escritos, Vol. 4). Rio de Janeiro: Forense Universitária.

Foucault, M. (2008a) Segurança, território, população (Curso no Collège de France, 1977-1978). São Paulo: Martins Fontes.

Foucault, M. (2008b). Nascimento da biopolítica (Curso no Collège de France, 1978-1979). São Paulo: Martins Fontes.

Guattari, F. \& Rolnik, S. (1986). Micropolítica: cartografias do desejo. Rio de Janeiro: Vozes.

Lemos, F. C. S \& Cardoso Jr., H. R. (2012). Problematizar. In T. M; G. Fonseca, M. L. Nascimento, \& C. Maraschin. (Orgs.). Pesquisar na diferença: um abecedário (pp. 191193). Porto Alegre: Sulina.

Lobo, L. F. (2008). Os infames da história: pobres, escravos e deficientes no Brasil. Rio de Janeiro: Lamparina.

Marafon, G. (2013). Vida em judicialização: efeito bullying como analisador. Tese de doutorado Não-publicada, Programa de Pós-Graduação em Psicologia, Universidade Federal Fluminense, Niterói.

Ramos do Ó, J. (2009). A "Criança problema" e o seu governo em Portugal e no Brasil (1880-1960): discursos e práticas. In J. Ramos de Ó, \& L. M. Carvalho. Emergência e circulação do conhecimento psicopedagógico moderno (1880-1960): estudos comparados Portugal-Brasil (pp. 15153). Lisboa: Educa.

Rizzini, I. (2009). Crianças e Menores - Do Pátrio Poder ao Pátrio Dever: Um Histórico da Legislação para a Infância no Brasil. In F. Pillotti, \& I. Rizzini, (Orgs.). A Arte de Governar Crianças. A história das Políticas Sociais, da Legislação e da Assistência a Infância no Brasil (pp. 97149). 2a ed. São Paulo: Cortez.

Truffaut, F. (1959). Os incompreendidos. [filme]. França.

Vianna, A. R. (1999). O mal que se adivinha: polícia e menoridade no Rio de Janeiro (1910-1920). Rio de Janeiro: Arquivo Nacional.

Giovanna Marafon: mestre em Educação pela Universidade Federal do Estado do Rio de Janeiro, doutora em Psicologia pela Universidade Federal Fluminense, pós-doutoranda no Departamento de Educação da Pontifícia Universidade Católica do Rio de Janeiro. 